\title{
In Vitro Antioxidant, Anti-inflammatory, and In Vivo Anticolitis Effects of Combretin A and Combretin B on Dextran Sodium Sulfate-Induced Ulcerative Colitis in Mice
}

\author{
Mbiantcha Marius $\left(\mathbb{D},{ }^{1}\right.$ Dawe Amadou, ${ }^{2}$ Atsamo Albert Donatien, ${ }^{3}$ Ateufack Gilbert, ${ }^{1}$ \\ Yousseu Nana William, ${ }^{1}$ Khalid Rauf, ${ }^{4}$ Mehreen Arif, ${ }^{4}$ Fanta Yadang Sabine Adeline, ${ }^{5}$ \\ Njoku Isaac Saint, ${ }^{6}$ Hamza Dar, ${ }^{4}$ Naeem Ur Rehman, ${ }^{4}$ and Izhar Ahmad ${ }^{4}$ \\ ${ }^{1}$ Laboratory of Animal Physiology and Phytopharmacology, Faculty of Science, University of Dschang, P.O. Box 67, \\ Dschang, Cameroon \\ ${ }^{2}$ Department of Chemistry, Higher Teachers Training College, University of Maroua, P.O. Box 55, Maroua, Cameroon \\ ${ }^{3}$ Laboratory of Animal Physiology, Faculty of Science, University of Yaounde I, PO Box 812, Yaound'e, Cameroon \\ ${ }^{4}$ Department of Pharmacy, COMSATS University Islamabad, Abbottababd Campus, \\ 22060 Abbottabad Khyber Pakhtunkhwa, Pakistan \\ ${ }^{5}$ Center for Research on Medicinal Plants and Traditional Medicine, Institute of Medical Research and Medicinal Plants Studies, \\ P.O. Box 13033, Yaounde, Cameroon \\ ${ }^{6}$ Department of Chemistry, University of Lagos, Akoka, Lagos, Nigeria
}

Correspondence should be addressed to Mbiantcha Marius; mbiantchamarius@yahoo.fr

Received 23 June 2020; Revised 30 August 2020; Accepted 9 October 2020; Published 7 November 2020

Academic Editor: Paolo Gionchetti

Copyright @ 2020 Mbiantcha Marius et al. This is an open access article distributed under the Creative Commons Attribution License, which permits unrestricted use, distribution, and reproduction in any medium, provided the original work is properly cited.

\begin{abstract}
Combretum fragrans (Combretaceae) is a Cameroonian medicinal plant containing various secondary metabolites and traditionally used for the treatment of several pathologies. Two cycloartane-type triterpenes, Combretin A and Combretin B, were isolated from this plant. This study was aimed at evaluating the anti-inflammatory, antioxidant, and anticolitis effects of these compounds. In vitro anti-inflammatory properties were evaluated by inhibition of cyclooxygenase, 5-lipoxygenase, and denaturation of the protein; antioxidant properties were assessed by using 1,1-diphenyl-2-picrylhydrazyl (DPPH), (2,2'-azino-bis(3ethylbenzthiazoline-6-sulphonic acid)) $\mathrm{ABTS}^{\bullet+}$, capacity tests ferric reducing antioxidant (FRAP), and trapping nitric oxide. For in vivo analysis, we used the model of ulcerative colitis induced by Dextran Sulfate Sodium (DSS). Studies of the antiinflammatory activity showed that Combretin A and Combretin B had maximal inhibitory activity on cyclooxygenase (71.92\% and $89.59 \%)$, 5-lipoxygenase (76.68\% and $91.21 \%)$, and protein denaturation (63.93\% and 87.78\%). Antioxidant activity on $\mathrm{DPPH}, \mathrm{ABTS}^{\bullet+}$, ferric reducing antioxidant capacity (FRAP), and nitric oxide scavenging showed that Combretin A and Combretin B showed good antioxidant activities. These compounds significantly reduced the signs of DSS-induced colitis in the treated animals by preventing the weight loss of the animals, by significantly reducing the disease activity index, improving the condition of the stool, preventing the reduction of the length of the colon, and preventing the degradation of the colon. This study revealed that Combretin A and Combretin B have anti-inflammatory, antioxidant, and curative properties against colitis experimentally induced by DSS in rats.
\end{abstract}

\section{Introduction}

Inflammatory bowel diseases, mainly represented by ulcerative colitis and Crohn's disease, are chronic pathologies of the cell-mediated digestive tract which are accompanied by significant recurrent and chronic inflammation [1]. People with inflammatory bowel disease present a significant dysfunction of the immune system [2], and COX plays a very 
important role in the development and maintenance of ulcerative colitis [3]. In mammals, COX has two isoforms, COX-1 which is constitutive and COX-2 which is induced by the inflammatory response [3]. During the pathophysiology of inflammatory bowel diseases, inflammatory lesions trigger innate immune responses resulting in the production of chemokines and cytokines (TNF- $\alpha$, IL- 6, IL- $1 \beta$ ) by intestinal epithelium cells and the macrophages that will be responsible for the development of the adaptive immune system [4]. Thus, in the absence of treatment, intestinal lesions can occur following an exaggeration of the inflammatory response [5]. Numerous studies have shown that several natural compounds which have the capacity to inhibit the production of cytokines and the activity of COX-2 have an important therapeutic efficacy against inflammatory bowel diseases [6].

When our body is attacked by bacteria and viruses, the inflammatory process is activated with the production of white blood cells and other protective substances [7]. These inflammatory reactions set up to protect our organism which involves reactive oxygen species starting with the activation of leukocytes. Thus, the effect of a product for the modulation of inflammatory processes could be provided by its antioxidant properties [8]. The release of elements such as hydroxyl radicals, superoxide, and/or peroxyl radicals is responsible for the development of oxidative stress. These reactive oxygen species play a very important role in the pathophysiology of many diseases (coronary artery disease, neurodegenerative disorders, aging, atherosclerosis, inflammation, chronic pain, Alzheimer's disease, cancer, and cataracts) [9, 10]. During the development of many inflammatory disorders, the phagocytes are activated; hydrogen peroxides (free radical species) such as the $\mathrm{O}_{2}$ and $\bullet \mathrm{OH}$ radicals are released [11] and destroy the membrane by lipid peroxidation following a direct or indirect oxidative action. Tissue damage leads to the development of an inflammatory reaction with the production of chemotactic factors and numerous mediators [12].

In order to carry out scientific studies on inflammatory bowel disease, several animal models have been developed such as models transferred by adoption, chemically induced models, genetically modified models, and spontaneous models [13]. The DSS-induced colitis model (Dextran Sodium Sulfate), which is a very simple and reproducible model, is commonly used to assess the pathogenesis of ulcerative colitis and also to test new treatments potentially effective against ulcerative colitis [14]. Indeed, concerning this model, 1 to $5 \%$ of DSS is added to the drinking water which is given to the animals for several days; after a few days, animals develop symptoms such as diarrhea, loss of body weight, ulcers, bleeding, and mucosal lesions that are characteristics of human ulcerative colitis [15]. These symptoms can be relieved with many drug treatments; however, these different modern treatments have many side effects and increased tolerance in patients with ulcerative colitis [16]. For these different reasons, new therapeutic approaches remain to be developed and are currently necessary for the relief of people suffering from ulcerative colitis.

In the treatment of inflammatory disorders, a product capable of trapping reactive oxygen species, inhibiting the production of cytokines and COX, can be very beneficial.
Combretum fragrans F. HOFFM (Combretaceae), a plant containing several classes of compounds such as saponins, steroids, flavonoids, triterpenes, and tannins [17, 18], is used in Africa to treat diarrhea, leprosy, pain, cough, inflammation, and chronic diabetic wounds. Two cycloartane-type triterpenes named Combretin A and Combretin B were isolated from the leaves of this species and showed in vitro inhibitory properties for the production of NO, TNF alpha, ROS, and immunomodulatory properties; they also showed analgesic, anti-inflammatory, antihypernociceptive, and neuroprotective properties [18-20]. However, the ability of Combretin A and Combretin B to inhibit the onset of symptoms of DSS-induced colitis has not been studied. The results of our previous work prompted us to check whether Combretin A and Combretin B could have anti-inflammatory activity in the model of DSS-induced ulcerative colitis in mice.

\section{Methods}

2.1. Reagents, Chemicals, and Equipment. 1,1-Diphenyl-2picrylhydrazyl (DPPH) was obtained from Sigma Aldrich (St. Louis, MO, USA). Sodium nitroprusside was purchased from Merck Ltd., India, Mumbai. Phosphoric acid, sodium hydroxide, sodium linoleate, sulfanilamide, sulfuric acid, linoleic acid, ascorbic acid, and arachidonic acid were purchased from SD Fine Chem. Ltd, Mumbai. Thiobarbituric acid, lipopolysaccharide, hemoglobin, ethylenediaminetetraacetic acid, and bovine albumin were obtained from Central Drug House Pvt. Ltd., New Delhi. Trypsin and casein were obtained from Hi-Media Lab. Ltd., Mumbai. N-(1-naphthy1)ethylenediamine dihydrochloride, potassium persulfate, potassium phosphate buffer, glutathione, and benzene were obtained from LOBA CHEME Pvt. Ltd. Mumbai. The chemicals include the following products: methanol, dimethyl sulfoxide (DMSO), and sodium chloride and were purchased from Geochim Sarl, west region of Cameroon. DSS was purchased from Tokyo Chemical Industry Co., Ltd., Japan. Prednisolone (Solupred) and all other chemicals and reagents were pure analytical grade and obtained from local suppliers.

2.2. Plant Material, Extraction, and Isolation. The plant material, referenced to the national herbarium of Cameroon with number 30309/H.N.C. in the name of Combretum fragrans (Combretaceae), was used to isolate the pure compounds tested in this study. The fresh leaves of this plant were harvested in the city of Maroua located in the far north region (Cameroon) [18]. These leaves were macerated in methanol; the extract obtained was successively fractionated in hexane, AcOEt, and $\mathrm{BuOH}$. AcOEt fraction was subjected to conventional separation methods, and the isolated compounds (Combretin A and Combretin B) were described by usual spectroscopic methods [18].

2.3. In Vitro Assay. To develop the methodology of the study, Nguemnang et al. [21] was briefly followed.

\subsubsection{Anti-inflammatory Activity}

(1) Inhibition of Protein Denaturation. For the evaluation of anti-inflammatory properties, the protocol described by 
Padmanabhan and Jangle [22] was used with some modifications. One milliliter of test compounds or diclofenac sodium in different concentrations $(100,200,500$, and $1000 \mu \mathrm{g} / \mathrm{mL}$ ) was added to $1 \mathrm{~mL}$ aqueous solution of $5 \%$ bovine serum that was then incubated for 15 minutes at $27^{\circ} \mathrm{C}$. Distilled water and BSA mixture were used as control. For protein denaturation, the whole mixture was placed at $70^{\circ} \mathrm{C}$ for about 10 minutes. When the mixture is cooled down to room temperature, the activity of each mixture was measured at $660 \mathrm{~nm}$. All tests were performed in triplicate. The following formula was used to study percent inhibition:

$\%$ Inhibition $=\frac{\text { Absorbance of control }- \text { Absorbance of sample }}{\text { Absorbance of control }} \times 100$.

(2) Assay of Cyclooxygenase and 5-Lipoxygenase Inhibition. Lymphocyte culture preparation. For the culturing of human peripheral lymphocytes, RPMI 1640 (HIMEDIA) that was supplemented with streptomycin, penicillin, and fetal calf serum was used. Phytohemagglutinin (HIMEDIA) used mediated the cell proliferation. The culture was filtered (cellulose acetate $0.2 \mu \mathrm{m}$ pore, Sartorios) and incubated for 72 hours after the addition of plasma $\left(1 \times 10^{6}\right.$ cells $\left./ \mathrm{mL}\right)$. This culture was then activated by adding lipopolysaccharide $(1 \mu \mathrm{L})$ and incubated for 24 hours. After activation, Combretin A, Combretin B, and diclofenac were added in different concentrations $(100,200,500$, and $1000 \mu \mathrm{g} / \mathrm{mL}$ ) and incubated for 24 hours. These are then centrifuged for 10 minutes at $6000 \mathrm{rpm}$ for sedimentation. The supernatant was removed, and cell lysis buffer was added $(50 \mu \mathrm{L})$ and again centrifuged at $6000 \mathrm{rpm}$ for 10 minutes [23].

Assay of Cyclooxygenase. Cyclooxygenase assay was performed using Tris-HCl buffer, enzyme, hemoglobin, and glutathione. To this mixture, arachidonic acid and TCA $(10 \%$ in $1 \mathrm{~N} \mathrm{HCl}, 0.2 \mathrm{~mL})$ were added and incubated for 20 minutes at $37^{\circ} \mathrm{C}$. Then, to the mixture, TBA $(0.2 \mathrm{~mL})$ was added and heated in boiling water for 20 minutes. This is then cooled and centrifuged for 3 minutes at $1000 \mathrm{rpm}$. The supernatant was used to measure COX activity at $632 \mathrm{~nm}$ [23].

Assay of 5-lipoxygenase. Lipoxygenase assay was performed by mixing equal quantities of linoleic acid $(70 \mathrm{mg})$ and tween 20 in $4 \mathrm{~mL}$ of nonoxygenated water. To this mixture, sodium hydroxide $(0.5 \mathrm{~N})$ was added, and nonoxygenated water is added in a quantity sufficient to make a volume up to $25 \mathrm{~mL}$. The resulting solution will be divided into $0.5 \mathrm{~mL}$ portions and thoroughly rinsed with nitrogen and then left for freezing. A quartz cuvette $\left(25^{\circ} \mathrm{C}\right)$ with $1 \mathrm{~cm}$ optical pathway made it possible to carry out a reaction. The optic density (OD) was measured at $234 \mathrm{~nm}$ with a mixture containing sodium linoleate $(0.2 \mathrm{~mL})$, Tris buffer $(2.75 \mathrm{~mL}, \mathrm{pH} 7.4)$, and enzyme $(50 \mathrm{~mL})$ [23]. The percent inhibition was calculated by using the following equation:

$$
\text { \%inhibition }=\frac{\mathrm{OD}_{\text {control }}-\mathrm{OD}_{\text {sample }}}{\mathrm{OD}_{\text {control }}} \times 100 \text {. }
$$

\subsubsection{Antioxidant Activity}

(1) DPPH Radical Scavenging Activity. DPPH $24 \mathrm{mg}$ was dissolved in $100 \mathrm{~mL}$ methanol; this solution is then diluted to a point to obtain absorbance at $517 \mathrm{~nm}$ of about $0.98 \pm 0.02$ forming a working solution. From this working solution, $3 \mathrm{~mL}$ was mixed with $100 \mu \mathrm{L}$ of Combretin A, Combretin B, or standard solution $(1 \mathrm{mg} / \mathrm{mL})$, and absorbance was measured (517 nm for 30 minutes) [24]. The control contained $100 \mu \mathrm{L}$ methanol in place of the plant sample. The percentage of antiradical activity (antioxidant) was determined by the following formula:

$\begin{aligned} \% \text { antioxidant activity }= & \frac{\text { Absorbance }(\text { control })-\text { Absorbance }(\text { sample })}{\text { Absorbance }(\text { control })} \\ & \times 100 .\end{aligned}$

(2) ABTS • Decolorization Assay. ABTS $(7 \mathrm{mM})$ in a volume of $9.5 \mathrm{~mL}$ was taken and mixed with $245 \mu \mathrm{L}$ of potassium persulfate $(100 \mathrm{mM})$ that is supplemented to $10 \mathrm{~mL}$ with distilled water to form a working solution. This solution is left for 18 hours in dark at room temperature; after that, potassium phosphate buffer (0.1 M, pH 7.4) was introduced until an absorbance $(734 \mathrm{~nm})$ of about $0.70 \pm 0.02$ was obtained. The tested compounds were diluted in methanol to obtain concentrations of $0.1,0.25,0.5$, and $1 \mathrm{mg} / \mathrm{mL} .10 \mu \mathrm{L}$ of a sample was mixed with $2.99 \mathrm{~mL}$ of working solution and recorded at $734 \mathrm{~nm}$ [25]. The control was prepared by adding $10 \mu \mathrm{L}$ of methanol in place of the sample. The percentage of antioxidant activity was determined using the following formula:

$$
\begin{aligned}
\% \text { antioxidant activity }= & \frac{\text { Absorbance }(\text { control })-\text { Absorbance }(\text { sample })}{\text { Absorbance }(\text { control })} \\
& \times 100 .
\end{aligned}
$$

(3) Ferric Reducing Antioxidant Potential (FRAP). The working reagent was prepared by mixing acetate buffer $(25 \mathrm{~mL}$, $30 \mathrm{mM}, \mathrm{pH} 3.6)$, TPTZ $(2.5 \mathrm{~mL}, 10 \mathrm{mM})$, and iron chloride $(2.5 \mathrm{~mL}, \mathrm{mM})$ and incubated at $37^{\circ} \mathrm{C}(15$ minutes $)$. Concentrations between $50 \mathrm{mg} / \mathrm{L}$ and $500 \mathrm{mg} / \mathrm{L}$ of ascorbic acid produced a calibration curve [26]. The absorbance was measured at $593 \mathrm{~nm}$ for each specimen consisting of working reagent $(2.85 \mathrm{~mL})$, test compounds $(150 \mu \mathrm{L}, 0.1 \mathrm{mg} / \mathrm{mL})$ diluted in methanol, methanol $(150 \mu \mathrm{L})$, or stallion.

(4) Nitric Oxide Scavenging Assay. Sodium nitroprusside $(0.5 \mathrm{~mL}, 5 \mathrm{mmol} / \mathrm{L}, \mathrm{pH} 7.4)$ was combined at different concentrations $0.1,0.25,0.5$, and $1 \mathrm{mg} / \mathrm{mL}$ of test compounds, ascorbic acid, or an equivalent amount of methanol and incubated for 180 minutes $\left(25^{\circ} \mathrm{C}\right)$. Griess reagent $(1.5 \mathrm{~mL})$ consisting of sulfanilamide (1\%), phosphoric acid (2\%), and $N$-1-naphthylethylenediamine dihydrochloride $(0.1 \%)$ was 
added, and the mixture was again incubated for 30 minutes. Absorbance was measured at $546 \mathrm{~nm}$, and the percentage of activity was determined relative to the standard [27]. The following equation was used to show percent inhibition:

$$
\begin{aligned}
\% \text { nitric oxide scavenging }= & \frac{\text { Absorbance of control }- \text { Absorbance of test }}{\text { Absorbance of control }} \\
& \times 100 .
\end{aligned}
$$

\subsection{In Vivo Assay}

2.4.1. Experimental Animals. The blind behavioral evaluation technique was performed for the administration of different treatments. Mice (males and females), aged about 3 months and weighing between 25 and $30 \mathrm{~g}$, reared in an animal house (controlled temperature $\left(22 \pm 1^{\circ} \mathrm{C}\right)$ and a 12-hour light cycle/12 $\mathrm{h}$ in dark, with standard laboratory food and unlimited water) from the National Institutes of Health (NIH) Islamabad, Pakistan, were used for this test.

The minimum number of mice ( 6 animals per group) was granted by the National Institute of Health Institute (IACUC) Committee of National Institute of Health. In addition, the study protocols accepted by the Ethics Committee of the National Institute of Health Islamabad in Pakistan were used to assess the consistency of the effects of different treatments administered.

2.4.2. Experimental Colitis. For the induction of experimental colitis, 4\% DSS was used. Briefly, after an habituation period of one week, mice (42) were randomly divided into 7 groups (6 mice/group): untreated (no DSS), 4\% DSS $+2.5 \%$ DMSO $/ 2.5 \%$ tween, $4 \%$ DSS+prednisolone $(4 \mathrm{mg} / \mathrm{kg}), 4 \%$ DSS+Combretin A $(25 \mathrm{mg} / \mathrm{kg}), 4 \%$ DSS+Combretin A (50 mg/kg), 4\% DSS+Combretin B (25 mg/kg), and 4\% DSS +Combretin B $(50 \mathrm{mg} / \mathrm{kg})$. The untreated group received distilled water without DSS. For other groups, water bottles were filled with $4 \%$ DSS. Combretin A, Combretin B, prednisolone, and distilled water were administered orally from the $5^{\text {th }}$ day after the onset of colitis induction by DSS.

Mice were scored daily for 10 days based on body weight and stool formation (bloody or nonbloody). Stool formation, bloody stool scores, and weight loss were averaged to determine the Disease Activity Index (DAI). Scores were assessed as follows: bloody stools (0: negative, 2: positive, or 4: gross bleeding), weight change $(0:<1 \%, 1: 1-5 \%, 2: 5-10 \%, 3$ : $10-15 \%$, or $4:>15 \%$ ), and stool formation (0: normal, 2 : loose stools, or 4: diarrhea). On day 10, the mice were sacrificed under ether vapor anesthesia and the intestines were isolated [28].

The entire colon from the ileocolic junction to the anus was quickly removed, opened longitudinally along the mesenteric fixation line, then washed with saline in a reservoir of ice water and dried with filter paper; then, the total length of the two points was measured [29].

2.4.3. Macroscopic and Microscopic Evaluation of the Colon. The same colon removed, washed, and dried was photographed using a Canon camera (Cyber-shot, 7.2 megapixels,
China); then, the samples from this colon were fixed in $10 \%$ formalin buffered with PBS. The sections were made in pieces of $5 \mu \mathrm{m}$ each; then, staining was done with hematoxylineosin (H\&E) [29].

2.5. Statistical Analysis. All the data from in vitro tests indicate an average \pm SEM of triplicate. The differences between groups were assessed by one way ANOVA followed by the Tukey posttest; for in vivo test, data are presented in the form of an average of 6 mice \pm SEM, and the differences between groups were evaluated by ANOVA (two way) followed by Bonferroni posttest and ANOVA (one way) followed by Tukey's posttest. Significant differences were considered at $p<0.05$.

\section{Results}

\subsection{In Vitro Activity}

\subsubsection{Anti-inflammatory Activity}

(1) Inhibition of Protein Denaturation. Based on the results of this study, Combretin A and B effectively inhibited protein denaturation caused by heat. Table 1 thus shows a significant $(p<0.001)$ inhibition of $63.93 \%$ and $87.78 \%$, respectively, for Combretin A and B while diclofenac sodium at $1000 \mu \mathrm{g} / \mathrm{mL}$ produced an inhibition of $89.20 \%$.

(2) Cyclooxygenase Inhibitory Assay. Evaluation of cyclooxygenase activity determined the effect of both compounds on prostaglandin production. The results show that, at $1000 \mu \mathrm{g} / \mathrm{mL}$, Combretin A and B and Diclofenac sodium significantly inhibited $(p<0.001)$ the cyclooxygenase activity with $71.92 \%, 89.59 \%$, and $97.88 \%$, respectively (Table 1 ).

(3) 5-Lipoxygenase Inhibitory Assay. The evaluation of the activity of 5-lipoxygenase was used to study the effect of the compounds on the production of leukotrienes. It appears from this table that Combretin A and B, as well as diclofenac sodium, have a significant effect $(p<0.001)$ on 5lipoxygenase activity with an inhibition of $76.68 \%, 91.21 \%$, and $95.31 \%$, respectively (Table 1 ).

\subsubsection{Anti-oxidant Activity}

(1) ABTS $\bullet+$ Radical Decolorization Assay. It appears from Figure 1(a) that Combretin A and B and vitamin C (used as a reference substance) showed significant antioxidant activity on the relative recovery capacity of ABTS generated in the aqueous phase.

(2) DPPH Radical Scavenging Activity. The results presented in Figure 1(b) show the activity of Combretin A and B in free radical scavenging by the DPPH test. It appears that Combretin $A$ and $B$ and vitamin $C$ at the concentration of $1 \mathrm{mg} / \mathrm{mL}$ showed a significant activity $(p<0.001)$ with inhibition percentages, respectively, of $91.38 \%, 57.83 \%$, and $95.15 \%$.

(3) Ferric Reducing Antioxidant Potential (FRAP). The antioxidant capacity of Combretin $\mathrm{A}$ and $\mathrm{B}$ was determined 
TABLE 1: Effect of Combretin A and Combretin B on protein denaturation, cyclooxygenase (COX), and 5-lipoxygenase (LOX) inhibition.

\begin{tabular}{|c|c|c|c|c|c|c|c|}
\hline \multirow{2}{*}{ Treatment } & \multirow{2}{*}{ Dose $(\mu \mathrm{g} / \mathrm{mL})$} & \multicolumn{3}{|c|}{ Activity } & \multicolumn{3}{|c|}{ Inhibition (\%) } \\
\hline & & Protein denaturation & COX & 5-LOX & Protein denaturation & $\mathrm{COX}$ & 5-LOX \\
\hline Control & - & $0.518 \pm 0.004$ & - & - & - & - & - \\
\hline \multirow{4}{*}{ Diclofenac } & 100 & $0.133 \pm 0.002^{\mathrm{c}}$ & - & - & 74.41 & - & - \\
\hline & 200 & $0.121 \pm 0.002^{c}$ & - & - & 76.72 & - & - \\
\hline & 500 & $0.133 \pm 0.002^{c}$ & - & - & 81.48 & - & - \\
\hline & 1000 & $0.056 \pm 0.001^{c}$ & - & - & 89.19 & - & - \\
\hline \multirow{4}{*}{ Ibuprofen } & 100 & - & $0.11 \pm 0.006$ & $0.232 \pm 0.022$ & - & 83.51 & 83.16 \\
\hline & 200 & - & $0.018 \pm 0.001^{\mathrm{c}}$ & $0.038 \pm 0.001^{\mathrm{c}}$ & - & 88.79 & 87.41 \\
\hline & 500 & - & $0.011 \pm 0.44^{\mathrm{c}}$ & $0.029 \pm 0.005^{\mathrm{c}}$ & - & 93.06 & 91.36 \\
\hline & 1000 & - & $0.007 \pm 0.001^{\mathrm{c}}$ & $0.021 \pm 0.006^{\mathrm{c}}$ & - & 97.51 & 95.65 \\
\hline \multirow{4}{*}{ Combretin A } & 100 & $0.298 \pm 0.011^{\mathrm{c}}$ & $0.055 \pm 0.009^{\mathrm{b}}$ & $0.110 \pm 0.009^{\mathrm{b}}$ & 42.49 & 47.58 & 44.25 \\
\hline & 200 & $0.255 \pm 0.032^{\mathrm{c}}$ & $0.041 \pm 0.001^{\mathrm{c}}$ & $0.075 \pm 0.007^{\mathrm{c}}$ & 50.92 & 59.58 & 60.87 \\
\hline & 500 & $0.231 \pm 0.023^{\mathrm{c}}$ & $0.037 \pm 0.003^{c}$ & $0.064 \pm 0.003^{c}$ & 55.41 & 63.06 & 67.64 \\
\hline & 1000 & $0.187 \pm 0.007^{\mathrm{c}}$ & $0.029 \pm 0.001^{\mathrm{c}}$ & $0.046 \pm 0.003^{c}$ & 63.93 & 71.92 & 76.68 \\
\hline \multirow{4}{*}{ Combretin B } & 100 & $0.211 \pm 0.005^{\mathrm{c}}$ & $0.039 \pm 0.001^{\mathrm{c}}$ & $0.073 \pm 0.006^{\mathrm{c}}$ & 59.23 & 61.94 & 62.22 \\
\hline & 200 & $0.158 \pm 0.012^{c}$ & $0.030 \pm 0.003^{c}$ & $0.058 \pm 0.007^{\mathcal{c}}$ & 69.44 & 71.04 & 69.77 \\
\hline & 500 & $0.115 \pm 0.003^{c}$ & $0.020 \pm 0.001^{c}$ & $0.038 \pm 0.009^{c}$ & 77.82 & 80.58 & 81.15 \\
\hline & 1000 & $0.063 \pm 0.005^{\mathrm{c}}$ & $0.011 \pm 0.002^{c}$ & $0.018 \pm 0.005^{\mathrm{c}}$ & 87.78 & 89.59 & 91.21 \\
\hline
\end{tabular}

Each value represents the mean $\pm \mathrm{SEM} ;{ }^{\mathrm{b}} p<0.001,{ }^{\mathrm{c}} p<0.001$ : significant difference compared to the control group. The percentage values were obtained using various concentrations of test compounds, and readings are presented as the mean of triplicates.

using the FRAP assay (Figure 1(c)). Combretin B showed the highest and most significant antioxidant capacity $(p<0.001)$, followed by Combretin A. Both compounds exhibited a similar upward trend in activity with an increased concentration.

(4) Nitric Oxide Scavenging Assay. Table 2 shows the comparison between the inhibition percentages of the compounds tested with ascorbic acid. This table shows that Combretin $B$ activity was significantly greater than that of Combretin A in nitric oxide scavenging and that the activities of both compounds increased with increasing dose.

\subsection{In Vivo Activity}

3.2.1. Effect of Combretin $A$ and Combretin B on Body Weight. In the group treated with DSS, the recorded weight loss was significant $(p<0.001)$ from day 4 after administration of DSS (4\%), and this loss remained significant $(p<0.001)$ until day 10. Treatment with Combretin A and $\mathrm{B}$ (25 and $50 \mathrm{mg} / \mathrm{kg}$ ) reversed weight loss from day 7 . The effect of Combretin A and B $(50 \mathrm{mg} / \mathrm{kg})$ was greater than that of prednisolone $(4 \mathrm{mg} / \mathrm{kg})$, used as a reference substance (Figure 2(a)).

3.2.2. Effect of Combretin $A$ and Combretin B on the Disease Activity Index. The disease activity index scores increased significantly $(p<0.001)$ in all animals treated with DSS from the $2^{\text {nd }}$ day, as indicated by the incidence of diarrhea, weight loss, and bloody stools. However, Combretin A and B $(50 \mathrm{mg} / \mathrm{kg})$ and prednisolone $(4 \mathrm{mg} / \mathrm{kg})$ showed significant $(p<0.001)$ reduction of the severity of DSS-induced disease (Figure 2(b)).
3.2.3. Effect of Combretin A and Combretin B on Stool Condition. Figure 2(c) shows the stool condition of animals treated with Combretin A and B (25 and $50 \mathrm{mg} / \mathrm{kg}$ ) and prednisolone $(4 \mathrm{mg} / \mathrm{kg})$. It appears that the score increased significantly $(p<0.001)$ in all the animals treated on day 1 after the induction of colitis compared to the animals in the normal control group. On the $7^{\text {th }}$ day, the score of animals treated with the different compounds and with prednisolone was significant $(p<0.001)$ compared to that of animals in the negative control group. In addition, the effect of Combretin A and B $(50 \mathrm{mg} / \mathrm{kg})$ was greater than that of prednisolone.

3.2.4. Effect of Combretin A and Combretin B on the Length of the Colon. Regarding the length of the colon, we found that the colon was significantly $(p<0.001)$ shorter in the negative control than in the normal control. Interestingly, treatment with Combretin A and B $(50 \mathrm{mg} / \mathrm{kg}, p<0.001)$ and prednisolone $(4 \mathrm{mg} / \mathrm{kg}, p<0.01)$ prevented the shortening of the colon significantly (Figure 3(a)).

3.2.5. Macroscopic Assessment of Colon Damage. Figure 3(b) shows the macroscopic presentation of the intestine of the animals after the induction of colitis induced by DSS. DSS is found to cause bleeding development in animals in the negative control group. In contrast, the animals that received Combretin A and B (50 mg/kg) and prednisolone show no bleeding.

3.2.6. Effect of Combretin $A$ and Combretin $B$ on the Histopathological Score. We next performed a histological analysis by performing $\mathrm{H} \& \mathrm{E}$ staining. As shown in Figures 4(a) and 4(b), 4\% DSS treatment induced an 


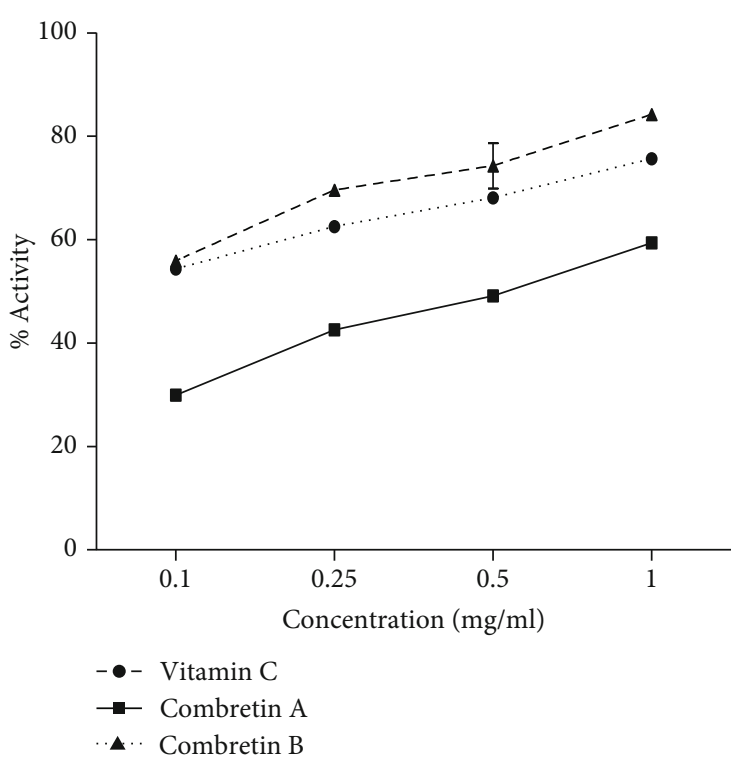

(a)

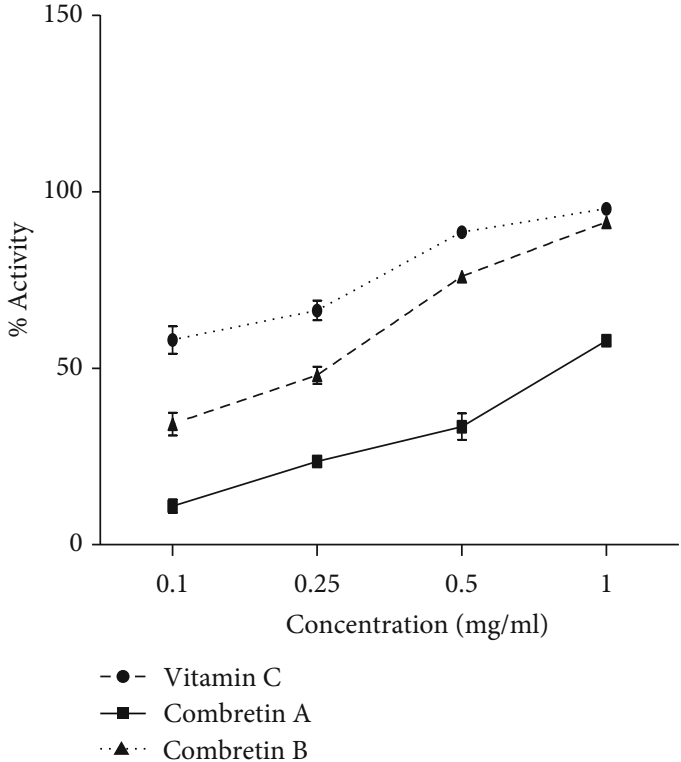

(b)

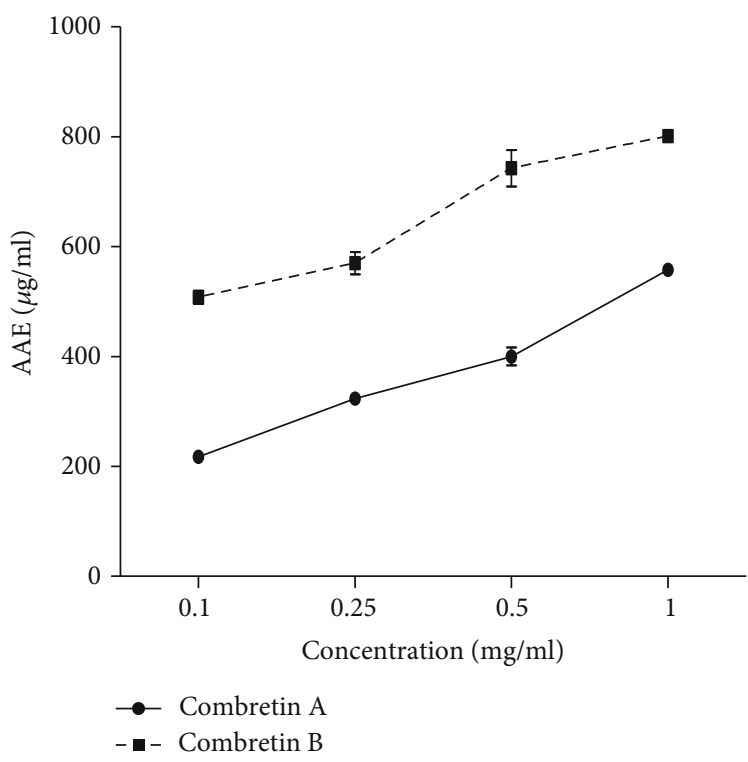

(c)

FIgURE 1: Antioxidant capacity of Combretin A and Combretin B on ABTS ${ }^{\bullet+}$ radical assay (a) expressed as percentage activity, and on DPPH assay (b) as a function of time for $30 \mathrm{~min}$ and FRAP assay in terms of Ascorbic Acid Equivalents (AAE). Each point represents the mean of three replications.

inflammatory response that affected colonic architecture, cell infiltration, crypt shortening or loss, and goblet cell depletion. Administration of Combretin A ( $50 \mathrm{mg} / \mathrm{kg})$, Combretin B $(50 \mathrm{mg} / \mathrm{kg})$, and prednisolone $(4 \mathrm{mg} / \mathrm{kg})$ significantly reduced the number of infiltrating cells, mucosal injury, and bleeding.

Histological examination of the colonic sections under light microscopy revealed that the untreated DSS mice exhibited typical inflammatory changes in the colonic architecture; the damage was assessed from histopathological scores for the colon (range 0 to 9). Compared with the normal control, the negative control mice showed a significant increase in the histopathological score of the disease (Figure 4). After treat- ment with Combretin A and B (25 and $50 \mathrm{mg} / \mathrm{kg}$ ) and prednisolone $(4 \mathrm{mg} / \mathrm{kg})$, the histopathological score of the disease decreased considerably showing a protective effect of the compounds against damage caused by DSS.

\section{Discussion}

In the present study, the results indicate that Combretin A and $\mathrm{B}$ possess good anti-inflammatory properties; however, Combretin B showed the best anti-inflammatory activity on several in vitro models such as inhibition of protein denaturation, inhibition of 5-LOX, and COX inhibition. Several antiinflammatory drugs such as diclofenac, phenylbutazone, 
TABle 2: Effect of Combretin A and Combretin B on nitric oxide scavenging activity.

\begin{tabular}{lccc}
\hline & $\begin{array}{c}\text { Concentration } \\
(\mathrm{mg} / \mathrm{mL})\end{array}$ & $\begin{array}{c}\text { Absorbance } \\
(660 \mathrm{~nm})\end{array}$ & $\begin{array}{c}\text { Inhibition } \\
(\%)\end{array}$ \\
\hline Control & - & $1.697 \pm 0.102$ & - \\
Vitamin C & 0.1 & $0.800 \pm 0.058^{\mathrm{c}}$ & $52.86 \pm 1.90$ \\
& 0.25 & $0.400 \pm 0.029^{\mathrm{c}}$ & $76.27 \pm 2.22$ \\
& 0.5 & $0.193 \pm 0.006^{\mathrm{c}}$ & $88.56 \pm 0.47$ \\
Combretin & 1 & $0.099 \pm 0.009^{\mathrm{c}}$ & $94.08 \pm 0.80$ \\
A & 0.1 & $1.136 \pm 0.055^{\mathrm{b}}$ & $32.28 \pm 6.65$ \\
& 0.25 & $0.873 \pm 0.062^{\mathrm{c}}$ & $48.41 \pm 3.34$ \\
Combretin & 1 & $0.780 \pm 0.075^{\mathrm{c}}$ & $54.22 \pm 1.59$ \\
B & 0.1 & $0.608 \pm 0.092^{\mathrm{c}}$ & $64.54 \pm 3.16$ \\
& 0.5 & $0.719 \pm 0.071^{\mathrm{c}}$ & $57.79 \pm 2.18$ \\
& 1 & $0.467 \pm 0.034^{\mathrm{c}}$ & $72.09 \pm 3.45$ \\
\hline
\end{tabular}

The values were obtained using various concentrations of test compounds, and reading is presented as mean \pm SEM of triplicates. ${ }^{b} p<0.01$ and ${ }^{c} p<0.001$ significantly different compared to control.

salicylic acid, and many more have shown an important ability to dose-dependently inhibit heat-induced protein denaturation [30]. The denaturation mechanism is involved in the alteration of electrostatic force, hydrogen, hydrophobic, and disulfide bonds [31]. Steroidal and nonsteroidal antiinflammatory drugs, commonly used for the management of inflammatory conditions, have the ability to bind to plasma albumin, preventing or inhibiting thermal denaturation of albumin [32]. Thus, in this study, diclofenac, used as a reference substance, significantly inhibited the denaturation of proteins. Known as a truly complex physiopathological response, inflammation involves a large production of free radicals derived from neutrophils, nitric oxide (NO), reactive oxygen species (ROS), prostaglandins, and cytokines during its process [33]. The pathogenesis of inflammatory diseases involves the overproduction of substances such as prostaglandin $\mathrm{I} 2$, prostaglandin $\mathrm{E} 2$, thromboxane $\mathrm{A} 2$, and leukotrienes from arachidonic acid through two metabolic pathways, the COX (cyclooxygenase) pathway and the 5LOX (5-lipoxygenase) pathway [34]. Substances capable of inhibiting the activities of COX and 5-LOX resulting in a significant reduction in the production of leukotrienes and prostaglandins produce a large spectrum of antiinflammatory activity and can be considered as having an excellent pharmacological safety profile in the clinic [35]. Ibuprofen, a nonsteroidal anti-inflammatory drug, is an inhibitor of COX which rapidly and reversibly and/or irreversibly seizes the active site of COX and acts as a competitive inhibitor of arachidonic acid oxygenation [36-38]. The inhibitory activity of Combretin A and B on protein denaturation, the cyclooxygenase pathway, and 5-lipoxygenase show that these two compounds are capable of significantly inhibiting the production of prostaglandins and leukotrienes, which confers to these two compounds anti-inflammatory properties. In addition, our previous work has shown that Combretin A and B are able to inhibit carrageenan-induced inflammation in rats in vivo and to inhibit the production of ROS, TNF- $\alpha$, and NO in vitro [19].

Antioxidant substances as well as free radical scavengers are very often used to mitigate certain inflammatory pathologies; since, during the inflammatory process, there is a large production of free radicals that have the power to maintain the skin process [39]. In this study, several tests were used to evaluate the antioxidant activity of Combretin A and B; it was to put in the presence of compounds the reaction of the $\mathrm{Fe}^{3+} /$ ferricyanide complex reduction in a ferrous form (ABTS test), the ion reduction reaction compounds with the formation of a ferric tripyridyltriazine complex $\left(\mathrm{Fe}^{2+}-\right.$ TPTZ) (FRAP test), and the radical reduction reaction DPPH $[40,41]$. Combretin A and B showed a very important antioxidant capacity in all test models used with a concentration-dependent activity. During the development of the inflammatory process, macrophages are activated with overproduction of $\mathrm{NO}$ from nitric oxide synthase (iNOS) which will be responsible for an increase in vasodilation, vascular permeability, endothelial and tissue lesions, and development of inflammation. In addition to its important proinflammatory role in the development of chronic inflammation, NO is a diffusible free radical, considered a pleiotropic inhibitor in neuronal signaling, regulation of cell-mediated toxicity, relaxation of smooth muscle, platelet inhibition, and as an effector molecule in biological systems such as antimicrobial and antitumor activities, neuronal messages, or vasodilation [42]. From this study, Combretin A and B significantly reduced the amount of nitrite produced by the decomposition of sodium nitroprusside in vitro, suggesting that the direct NO scavenging process may be responsible for $\mathrm{NO}$ deletion by both compounds.

In the present study, the administration of $4 \%$ DSS in drinking water led to the development of symptoms of ulcerative colitis (bloody diarrhea, weight loss, and shortening of the length of the colon) in all the mice in the group untreated; moreover, mice having received DSS and untreated also presented a higher DAI score and a histopathological score compared to normal mice. In this study, we showed that Combretin A and B inhibited experimental colitis, resulting in an overall attenuation of DAI inflammation, including colon length and changes in body weight. Oral administration of $4 \%$ DSS in mice causes acute colitis. Animals have shown a variety of clinical symptoms of inflammatory bowel disease, including diarrhea, bloody stools, and weight loss. A disease activity index score was used as a reliable tool to assess the extent of gastrointestinal disease in experimental DSS-induced colitis. At the end of the experimental period, clinical symptoms were more pronounced. Prednisolone used in this study as the reference drug exerts its antiinflammatory and immunosuppressive effect by inducing the gene expression of annexin therefore which have the main function the inhibition of the phospholipase A2 enzyme with the consequence of suppressing the synthesis of prostaglandins and leukotrienes by the arachidonic acid. 


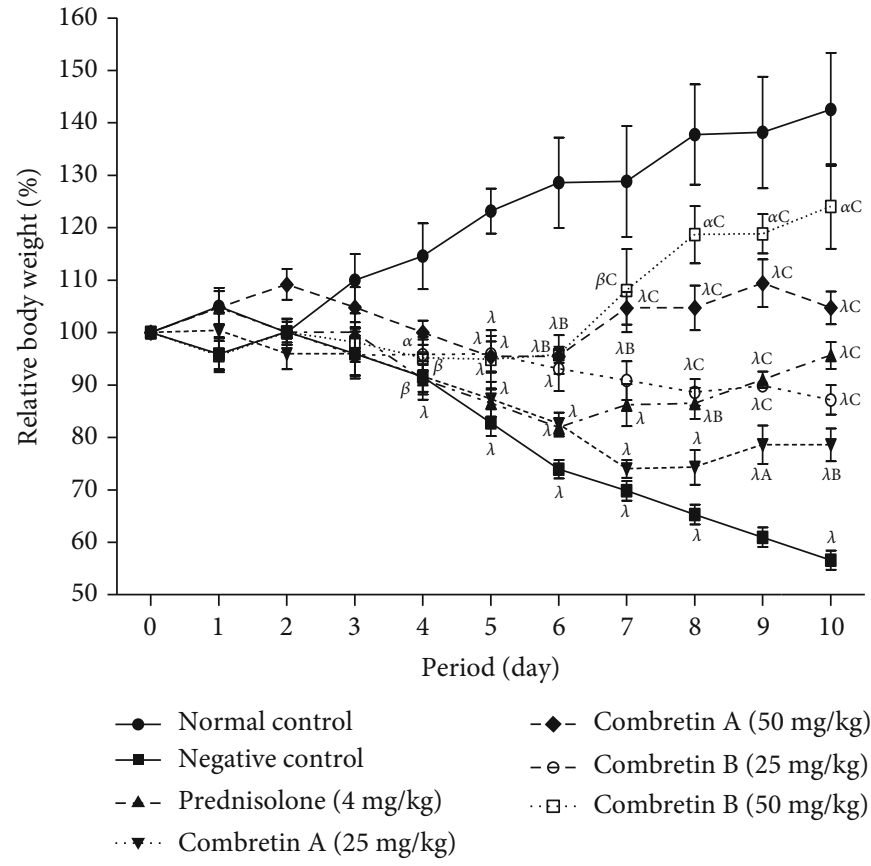

(a)

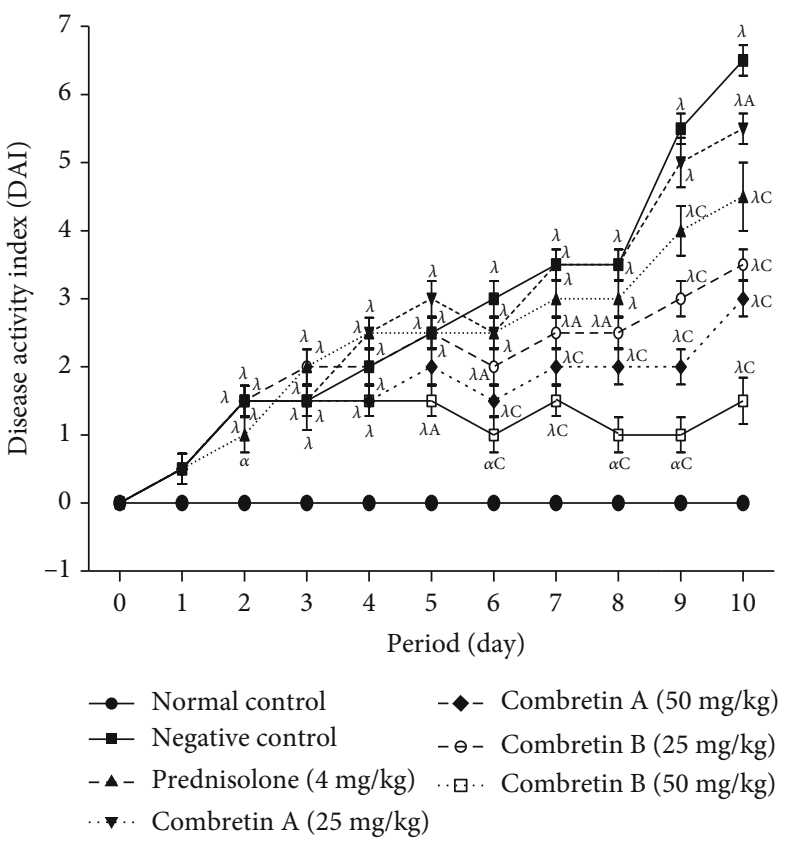

(b)

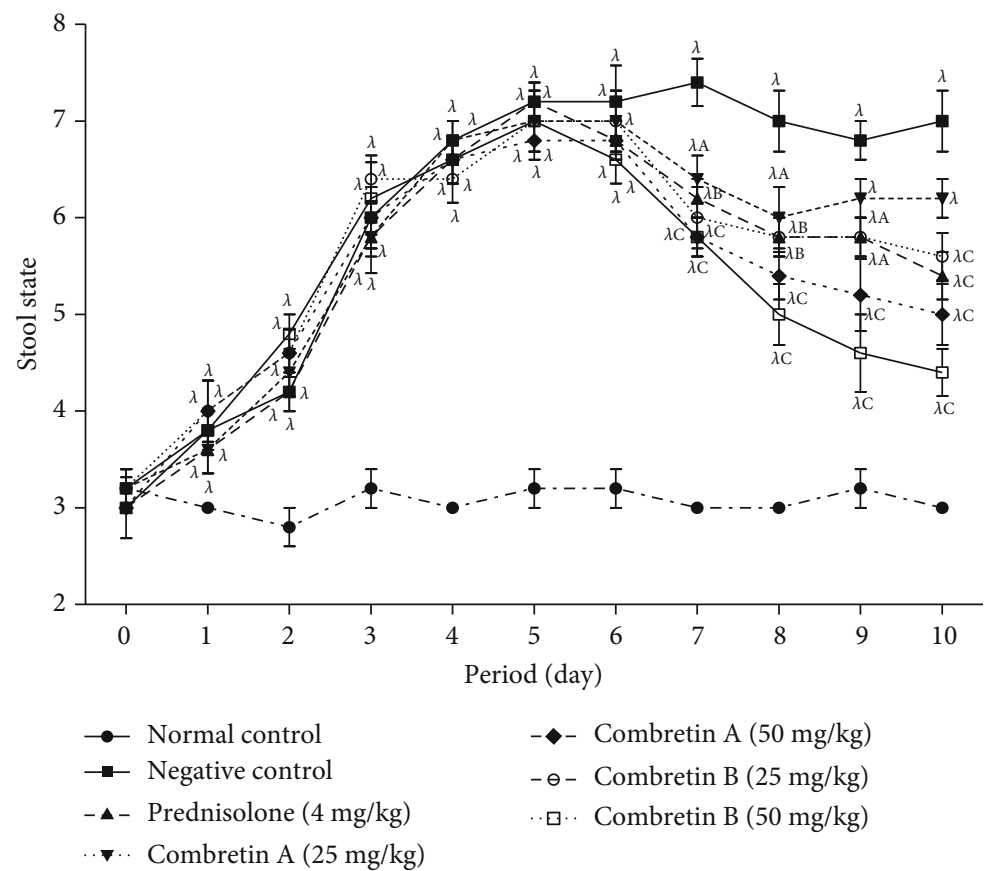

(c)

FIgURE 2: Effect of Combretin A and Combretin B on relative body weight (a), disease activity index (DAI) (b), and stool state (c) in DSSinduced colitis in rat. Values are expressed as mean \pm SEM for six animals and analyses by two-way ANOVA followed by Bonferroni post hoc test. ${ }^{\mathrm{A}} p<0.05,{ }^{\mathrm{B}} p<0.01,{ }^{\mathrm{C}} p<0.001$ : significant difference compared with negative control; ${ }^{\alpha} p<0.05,{ }^{\beta} p<0.01,{ }^{\lambda} p<0.001$ : significant difference compared with normal control.

Prednisolone can also act on macrophages and monocytes by blocking the synthesis and release of many proinflammatory cytokines (interleukin 1 (IL-1), interleukin 6 (IL-6), and tumor necrosis factor- $\alpha$ (TNF- $\alpha)$ ) [43]. In the study, prednisolone significantly reduced all the symptoms of DSS-induced colitis. However, mice treated with Combretin A and B significantly improved the clinical score, suggesting a protec- tive effect of these compounds in this model of colitis. Histological scores indicate that treatment with Combretin $\mathrm{A}$ and $\mathrm{B}$ reduced the damage to the mucous membranes. Ultimately, the results obtained indicate that treatment with Combretin A and B effectively attenuates established colonic inflammation and has a pronounced protective effect against colitis induced by DSS in mice. 


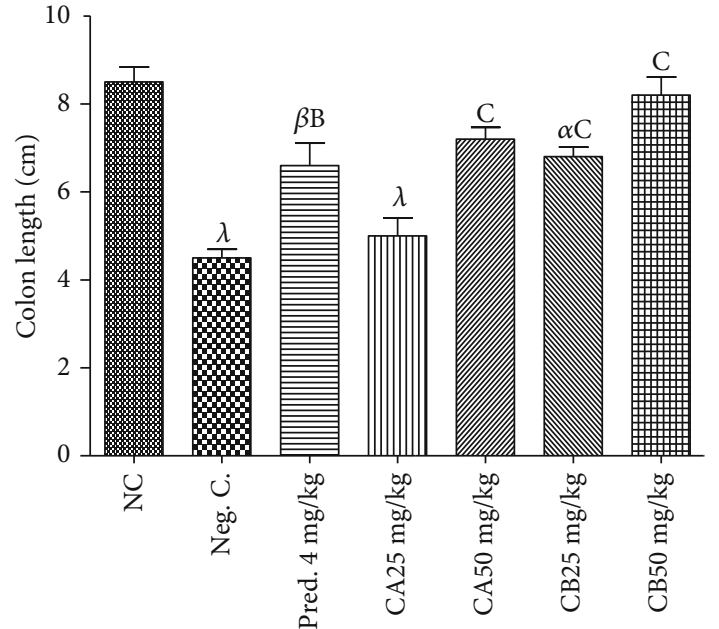

(a)

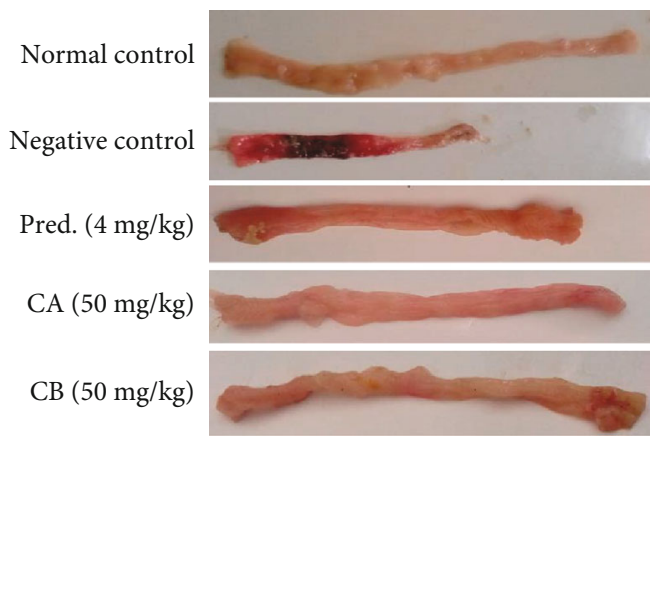

(b)

FIGURE 3: Effect of Combretin A and Combretin B on colon length in DSS-induced colitis in rats. Mice colons were isolated 10 days after DSS administration, and their lengths were measured. Values are expressed as mean \pm SEM for six animals and analyses by one-way ANOVA followed by Tukey post hoc test; ${ }^{\mathrm{B}} p<0.01,{ }^{\mathrm{C}} p<0.001$ : significant difference compared with negative control $(\mathrm{Neg} . \mathrm{C}){ }^{\alpha}{ }^{\alpha} p<0.05,{ }^{\beta} p<0.01$ ,${ }^{\lambda} p<0.001$ : significant difference compared with normal control (NC). CA: Combretin A; CB: Combretin B.

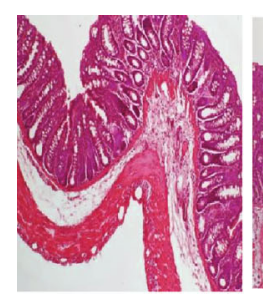

Normal control

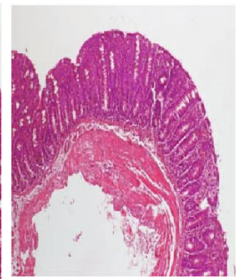

Negative control

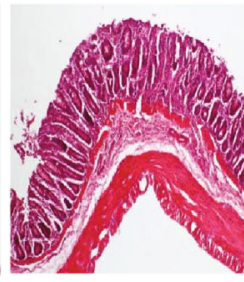

Pred. $4 \mathrm{mg} / \mathrm{kg}$

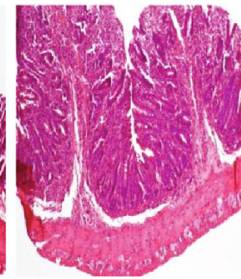

$\mathrm{CA} 50 \mathrm{mg} / \mathrm{kg}$

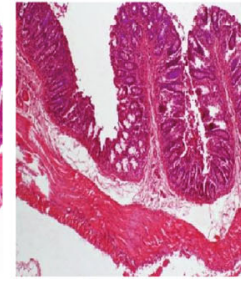

CB $50 \mathrm{mg} / \mathrm{kg}$

(a)

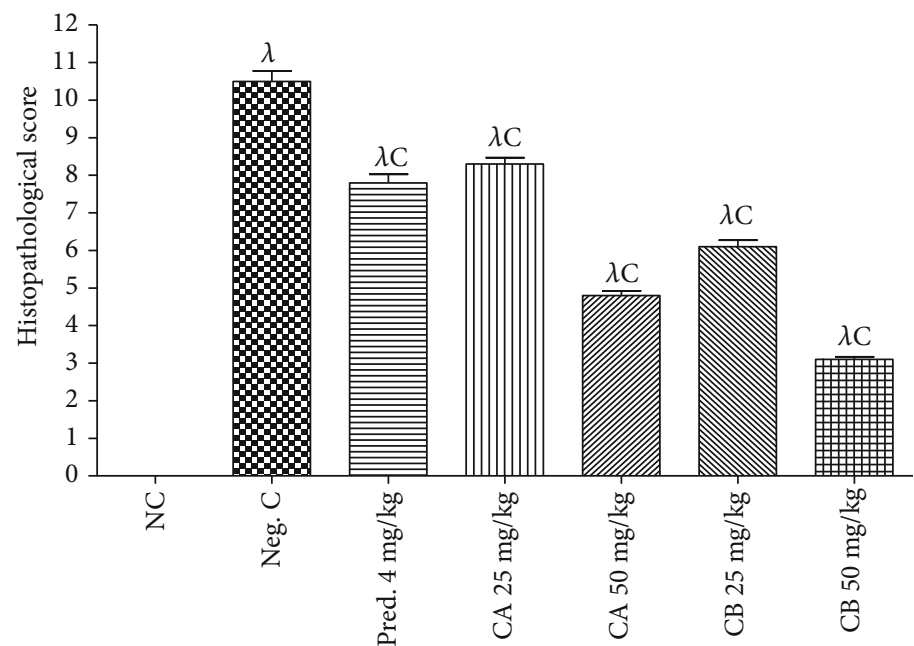

(b)

FIGURE 4: Effect of Combretin A and Combretin B on histopathological score in DSS-induced colitis in rat. (a) Representative hematoxylin and eosin (H\&E)-stained distal colon sections and (b) the histologic scores of rats. Values are expressed as mean \pm SEM for six animals and analyses by one-way ANOVA followed by the Tukey post hoc test; ${ }^{C} p<0.001$ : significant difference compared with negative control (Neg. C); ${ }_{\lambda} p<0.001$ : significant difference compared with normal control (NC). CA: Combretin A; CB: Combretin B.

Many cytokines such as TNF- $\alpha$, IL- 6 , and IL- $1 \beta$ play a key role in the pathogenicity of inflammatory bowel disease, in regulating inflammation of the intestinal mucosa, and in the integrity of the intestinal epithelium $[44,45]$. In addition, in people suffering from ulcerative colitis, the levels of TNF$\alpha$, IL-6, and IL- $1 \beta$ are greatly increased in the mucosa and 
serum [46]. Several studies have also shown that COX-2 expression is significantly elevated in animals with ulcerative colitis [47]. In addition, COX-2 and iNOS, known as inducible enzymes expressed rapidly by mononuclear macrophages, fibroblasts, or other cells after being stimulated in the body, are closely associated with the pathogenesis of ulcerative colitis. When iNOS and COX-2 are excessively released, oxidative damage can occur [48]. Likewise, ulcerative colitis is a peroxidative disease of the colon, and there are many intestinal pathological changes associated with the colitis process [49]. Oxidative stress is a response of the body stimulated by DSS. It can suppress endogenous defense systems that regulate the production of ROS [50]. High levels of ROS would have caused oxidative stress and DNA damage due to an imbalance between innate and exogenous antioxidants and ROS [51]. For these different reasons, several studies have shown that the regulation of these different pathways can be a solution for new therapeutic approaches against ulcerative colitis; thus, resveratrol exerts its effect against ulcerative colitis by increasing the expression of the SIRT1 gene, inducing the drop in the expression of $\mathrm{p}-\mathrm{IkB} \alpha$ as well as of COX-2 [52], while proto-catechic acid inhibits the production of inflammatory cytokines as well as COX-2 and iNOS to relieve patients with ulcerative colitis [53]. In previous studies, Combretin A and Combretin B have shown their ability to inhibit the production of NO, TNF alpha, and ROS, as well as their immunomodulatory properties [19], while in the present study, Combretin A and B have shown antiinflammatory and antioxidant properties. These results suggest that the effect of Combretin A and Combretin B against DSS-induced ulcerative colitis may be closely associated with their regulatory effect on inflammatory cytokines, iNOS activity, COX-2 expression, ROS, and the antioxidant system.

\section{Conclusion}

The anti-inflammatory and antioxidant properties in vitro, followed by the in vivo anticolitic properties of Combretine $\mathrm{A}$ and $\mathrm{B}$, were demonstrated in this study. The antiinflammatory potentials of Combretin A and Combretin B were clearly described in the test for inhibition of denaturation of proteins, cyclooxygenase, and 5-lipoxygenase. The potential for trapping antioxidants and free radicals is clearly revealed in the $\mathrm{DPPH}, \mathrm{ABTS}^{\bullet+}$, power reduction, and nitric oxide trapping tests. We have shown that Combretin A and Combretin B exert an inhibitory effect on the pathogenesis of colitis, improving colon shortening, body weight, DAI, and histopathological scores in mice with DSS-induced colitis.
Abbreviations
5-LOX: 5-Lipoxygenase
ANOVA: Analysis of variance
COX: Cyclooxygenase
DAI: Disease activity index
DMSO: Dimethyl sulfoxide
DPPH: 1,1-Diphenyl-2-picrylhydrazyl
DSS: $\quad$ Dextran sulfate sodium

ECACC: European collection of cell cultures

FRAP: Ferric reducing antioxidant capacity

$\mathrm{H} \& \mathrm{E}: \quad$ Hematoxylin and eosin

IL: Interleukin

NIH: National Institutes of Health

NO: $\quad$ Nitrite oxide

OD: $\quad$ Optic density

ROS: $\quad$ Reactive oxygen species

TNF- $\alpha$ : Tumor necrosis factor alpha.

\section{Data Availability}

The datasets used and/or analyzed during the current study are available from the corresponding author on reasonable request.

\section{Ethical Approval}

To demonstrate the coherent effects of our different compounds, the minimum possible of animals as the intensity of nociceptive stimuli was used. All tests were achieved using mature male and female mice ( 3 months old; $25-35 \mathrm{~g}$ ), bred in the animal house facility (controlled temperature $\left(22 \pm 1^{\circ} \mathrm{C}\right) ; 12 \mathrm{~h}$ light $/ 12 \mathrm{~h}$ dark cycle with standard lab chow and water ad libitum) of the National Institute of Health (NIH), Islamabad, Pakistan. The treatment of animals was in agreement with the Institutional Animal Care and Use Committee (IACUC) of the National Institute of Health, and the study protocols accepted by the ethics committee of National Institute of Health, Islamabad, Pakistan.

\section{Conflicts of Interest}

Mbiantcha Marius, Dawe Amadou, Atsamo Albert Donatien, Ateufack Gilbert, Yousseu Nana William, Khalid Rauf, Mehreen Arif, Fanta Yadang Sabine Adeline, Njoku Isaac Saint, Hamza Dar, Naeem Ur Rehman, and Izhar Ahmad have no conflicts of interest or financial ties to disclose.

\section{Authors' Contributions}

$\mathrm{MM}, \mathrm{DA}, \mathrm{KR}$, and $\mathrm{AAD}$ designed and performed the study and performed the procedures. MM, AG, MA, FYSA, and NIS collected and analyzed the data. MM, YNW, HD, NUR, and IA drafted the manuscript and revised it critically. The authors read and approved the final manuscript.

\section{Acknowledgments}

The authors would like to thank the study participants. The authors wish to express their gratitude to TWAS (Academy of Science of Developing Countries) and COMSATS Institute of Information Technology staff members for the in vitro part. This manuscript research project was supported by the TWAS (Academy of Science of Developing Countries) and the COMSATS University Islamabad, under the Postdoctoral Fellowship Award to Mbiantcha Marius (RF no: 3240287152). 


\section{References}

[1] M. S. Geier, R. N. Butler, and G. S. Howarth, "Inflammatory bowel disease: current insights into pathogenesis and new therapeutic options; probiotics, prebiotics and synbiotics," International Journal of Food Microbiology, vol. 115, no. 1, pp. 1-11, 2007.

[2] Y. Z. Zhang and Y. Y. Li, "Inflammatory bowel disease: pathogenesis," World Journal of Gastroenterology, vol. 20, no. 1, pp. 91-99, 2014.

[3] E. J. Shin, M. J. Sung, H. J. Yang, M. S. Kim, and J. T. Hwang, "Boehmeria nivea attenuates the development of dextran sulfate sodium-induced experimental colitis," Mediator of Inflammation, vol. 2014, article 231942, 7 pages, 2014.

[4] F. Rieder, T. Karrasch, S. Ben-Horin et al., "Results of the 2nd scientific workshop of the ECCO (III): basic mechanisms of intestinal healing," Journal of Crohn's and Colitis, vol. 6, no. 3, pp. 373-385, 2012.

[5] R. S. Blumberg, "Inflammation in the intestinal tract: pathogenesis and treatment," Digestive Diseases, vol. 27, no. 4, pp. 455-464, 2009.

[6] F. Algieri, A. Rodriguez-Nogales, N. Garrido-Mesa et al., "Intestinal anti-inflammatory activity of the Serpylli herba extract in experimental models of rodent colitis," Journal of Crohn's and Colitis, vol. 8, no. 8, pp. 775-788, 2014.

[7] M. Srividya Chandra, "In vitro anti-inflammatory activity of some wild fruits of Karnataka," in Biological, Environment and Food Engineering-2015, pp. 48-50, 2015.

[8] S. A. Uma and O. Bharti, "In-vitro 5-lipoxygenase inhibition of polyphenolic antioxidants from undomesticated plants of South Africa," Journal of Medicinal Plant Research, vol. 2, pp. 207-212, 2008.

[9] J. Burns, P. T. Gardner, D. Matthews, G. G. Duthie, M. E. Lean, and A. Crozier, "Extraction of phenolics and changes in antioxidant activity of red wines during vinification," Journal of Agricultural and Food Chemistry, vol. 49, no. 12, pp. 57975808, 2001.

[10] O. I. Aruoma, "Free radicals, oxidative stress and antioxidants in human health and disease," Journal of the American Oil Chemists' Society, vol. 75, no. 2, pp. 199-212, 1998.

[11] B. Gilham, K. Papachristodoulou, and J. H. Thomas, Wills'Biochemical Basis of Medicine, Butterworth-Heinemenn, Oxford, 1997.

[12] D. A. Lewis, "Anti-inflammatory drugs from plant and marine sources," Agents and Actions Supplements, vol. 27, pp. 3-373, 1989.

[13] R. S. Cotran, V. Kumar, and S. L. Robbins, Robbins, pathologic basis of disease, W.B. Saunders Company, Philadelphia, 9th edition, 1994.

[14] H. Xiao, "Therapeutic effects and the underlying mechanisms of qing-dai powder against experimental colitis in mice," thesis of doctor of philosophy, Hong Kong Baptist University, 2015.

[15] L. Solomon, S. Mansor, P. Mallon et al., "The dextran sulphate sodium (DSS) model of colitis: an overview," Comparative Clinical Pathology, vol. 19, no. 3, pp. 235-239, 2010.

[16] A. Mizoguchi, "Animal models of inflammatory bowel disease," Progress in Molecular Biology and Translational Science, vol. 105, pp. 263-320, 2011.

[17] P. Fyhrquist, L. Mwasumbi, C. A. Hæggstrom, H. Vuorela, R. Hiltunen, and P. Vuorela, "Antifungal activity of selected species of Terminalia, Pteleopsis and Combretum (Combreta- ceae) collected in Tanzania," Pharmaceutical Biology, vol. 42, no. $4-5$, pp. $308-317,2008$.

[18] A. Dawe, K. G. D. Wabo Fotso, J. J. Bankeu Kezetas, Y. Fawaia, M. Alid Shaiq, and B. Ngadjuie Tchaleu, "Combretins A and B, new cycloartane-type triterpenes fromCombretum fragrans," Helvetica Chimica Acta, vol. 99, no. 8, pp. 617-620, 2016.

[19] M. Mbiantcha, J. Almas, A. Dawe, A. Faheem, and Z. Sidra, "Analgesic, anti-inflammatory and anticancer activities of Combretin A and Combretin B isolated from Combretum fragrans F. HOFFM (Combretaceae) leaves," Inflammopharmacology, vol. 26, no. 6, pp. 1429-1440, 2018.

[20] M. Mbiantcha, R. Khalid, A. Dawe et al., "Antihypernociceptive and neuroprotective effects of Combretin A and Combretin B on streptozotocin-induced diabetic neuropathy in mice," Naunyn-Schmiedeberg's Archives of Pharmacology, vol. 392, no. 6, pp. 697-713, 2019.

[21] S. F. Djuichou Nguemnang, E. G. Tsafack, M. Mbiantcha et al., "In vitro anti-inflammatory and in vivo antiarthritic activities of aqueous and ethanolic extracts of Dissotis thollonii Cogn. (Melastomataceae) in rats," Evidence-Based Complementary and Alternative Medicine, vol. 2019, Article ID 3612481, 17 pages, 2019.

[22] P. Padmanabhan and S. N. Jangle, "Evaluation of in-vitro antiinflammatory activity of herbal preparation, a combination of four medicinal plants," International Journal of Basic and Applied Medical Sciences, vol. 2, no. 1, pp. 109-116, 2012.

[23] V. Viji and A. Helen, "Inhibition of lipoxygenases and cyclooxygenase-2 enzymes by extracts isolated from Bacopa monniera (L.) Wettst," Journal of Ethnopharmacology, vol. 118, no. 2, pp. 305-311, 2008.

[24] N. A. Shah, M. R. Khan, B. Ahmad, F. Noureen, U. Rashid, and R. A. Khan, "Investigation on flavonoid composition and anti free radical potential of Sida cordata," BMC Complementary and Alternative Medicine, vol. 13, no. 1, 2013.

[25] R. Re, N. Pellegrini, A. Proteggente, A. Pannala, M. Yang, and C. Rice-Evans, "Antioxidant activity applying an improved ABTS radical cation decolorization assay," Free Radical Biology and Medicine, vol. 26, no. 9-10, pp. 1231-1237, 1999.

[26] I. F. F. Benzie and J. J. Strain, "[2] Ferric reducing/antioxidant power assay: direct measure of total antioxidant activity of biological fluids and modified version for simultaneous measurement of total antioxidant power and ascorbic acid concentration," Methods in Enzymology, vol. 299, pp. 15-27, 1999.

[27] M. V. Anoop and A. R. Bindu, "In-vitro anti-inflammatory activity studies on Syzygium zeylanicum (L.) DC leaves," International Journal of Pharmaceutical Review and Research, vol. 4, no. 8, pp. 18-27, 2015.

[28] M. Rodriguez-Canales, R. Jimenez-Rivas, M. M. CanalesMartinez et al., "Protective effect of Amphipterygium adstringens extract on dextran sulphate sodium-induced ulcerative colitis in mice," Mediators of Inflammation, vol. 2016, Article ID 8543561, 12 pages, 2016.

[29] C. F. Adjouzem, A. Gilbert, M. Mbiantcha et al., "Effects of aqueous and methanolic extracts of stem bark of Alstonia boonei De wild. (Apocynaceae) on dextran sodium sulfateinduced ulcerative colitis in Wistar rats," Evidence-Based Complementary and Alternative Medicine, vol. 2020, Article ID 4918453, 15 pages, 2020.

[30] Y. Mizushima and M. Kobayashi, "Interaction of antiinflammatory drugs with serum proteins, especially with some 
biologically active proteins," Journal of Pharmaceutical Sciences, vol. 20, pp. 169-173, 1968.

[31] N. H. Grant, H. E. Alburn, and C. Kryzanauskas, "Stabilization of serum albumin by anti-inflammatory drugs," Biochemical Pharmacology, vol. 19, no. 3, pp. 715-722, 1970.

[32] Y. A. Bailey-Shaw, L. A. D. Williams, C. E. Green, S. Rodney, and A. M. Smith, "In-vitro evaluation of the antiinflammatory potential of selected Jamaican plant extracts using the bovine serum albumin protein denaturation assay," International Journal of Pharmaceutical Sciences Review and Research, vol. 47, no. 1, pp. 145-153, 2017.

[33] M. M. Mannan, M. Maridass, and B. Victor, "A review on the potential uses of ferns," Ethnobotanical Leaflets, vol. 12, pp. 281-285, 2008.

[34] G. Ghosh, P. Panda, M. Rath, A. Pal, T. Sharma, and D. Das, "GC-MS analysis of bioactive compounds in the methanol extract of Clerodendrum viscosum leaves," Pharmacognosy Research, vol. 7, no. 1, pp. 110-113, 2015.

[35] F. M. Frey and R. Meyers, "Antibacterial activity of traditional medicinal plants used by Haudenosaunee peoples of New York State," BMC Complementary and Alternative Medicine, vol. 10, no. $1,2010$.

[36] J. K. Gierse, C. M. Koboldt, M. C. Walker, K. Seibert, and P. C. Isakson, "Kinetic basis for selective inhibition of cyclo-oxygenases," Biochemical Journal, vol. 339, no. 3, pp. 607-614, 1999.

[37] J. J. Prusakiewicz, K. C. Duggan, C. A. Rouzer, and L. J. Marnett, "Differential sensitivity and mechanism of inhibition of COX-2 oxygenation of arachidonic acid and 2arachidonoylglycerol by ibuprofen and mefenamic acid," Biochemistry, vol. 48, no. 31, pp. 7353-7355, 2009.

[38] R. M. Botting, "Inhibitors of cyclooxygenases: mechanisms, selectivity and uses," Journal of physiology and pharmacology, vol. 57, no. 5, pp. 113-124, 2006.

[39] K. Tsuzuki, A. Ohashi, Y. Arai et al., "Triterpenoids from Adiantum caudatum," Phytochemistry, vol. 58, no. 2, pp. 363-367, 2001.

[40] N. Liang and D. Kitts, "Antioxidant property of coffee components: assessment of methods that define mechanisms of action," Molecules, vol. 19, no. 11, pp. 19180-19208, 2014.

[41] D. Ahmed and H. Mir, "Study of antioxidant, anti-protease and anti-urease potential of Schiff bases of acetophenone with different amines," Journal of the Chemical Society of Pakistan, vol. 36, pp. 915-921, 2014.

[42] N. Balakrishnan, A. B. Panda, N. R. Raj, A. Shrivastava, and R. Prathani, "The evaluation of nitric oxide scavenging activity of Acalypha indica Linn root," Asian Journal of Research in Chemistry, vol. 2, pp. 148-150, 2009.

[43] E. A. Strohmayer and L. R. Krakoff, "Glucocorticoids and cardiovascular risk factors," Endocrinology and Metabolism Clinics of North America, vol. 28, pp. 409-427, 2011.

[44] S. H. Lee, "Intestinal permeability regulation by tight junction: implication on inflammatory bowel diseases," Intestinal Research, vol. 13, no. 1, pp. 11-18, 2015.

[45] R. Francescone, V. Hou, and S. I. Grivennikov, "Cytokines, IBD, and colitis-associated cancer," Inflammatory bowel disease, vol. 21, no. 2, pp. 409-418, 2015.

[46] U. Colitis-Pathophysiology, "Inflammatory bowel disease part I: ulcerative colitis-pathophysiology and conventional and alternative treatment options," Alternative Medicine Review, vol. 8, no. 3, pp. 247-283, 2003.
[47] A. R. Martín, I. Villegas, M. Sánchez-Hidalgo, and C. A. de la Lastra, "The effects of resveratrol, a phytoalexin derived from red wines, on chronic inflammation induced in an experimentally induced colitis model," British Journal of Pharmacology, vol. 147, no. 8, pp. 873-885, 2006.

[48] Z. Z. Mo, Z. X. Lin, Z. R. Su et al., “Angelica sinensis supercritical fluid CO2 extract attenuates D-galactose-induced liver and kidney impairment in mice by suppressing oxidative stress and inflammation," Journal of Medicinal Food, vol. 21, no. 9, pp. 887-898, 2018.

[49] E. Kuwahara, Y. Murakami, T. Nakamura et al., "Factors associated with exacerbation of newly diagnosed mild ulcerative colitis based on a nationwide registry in Japan," Journal of Gastroenterology, vol. 52, no. 2, pp. 185-193, 2017.

[50] A. Bhattacharyya, R. Chattopadhyay, S. Mitra, and S. E. Crowe, "Oxidative stress: an essential factor in the pathogenesis of gastrointestinal mucosal diseases," Physiological Reviews, vol. 94, no. 2, pp. 329-354, 2014.

[51] A. Rezaie, R. D. Parker, and M. Abdollahi, "Oxidative stress and pathogenesis of inflammatory bowel disease: an epiphenomenon or the cause?," Digestive Diseases and Sciences, vol. 52, no. 9, pp. 2015-2021, 2007.

[52] U. P. Singh, N. P. Singh, B. Singh et al., "Resveratrol (trans$3,5,4^{\prime}$-trihydroxystilbene) induces silent mating type information regulation-1 and down-regulates nuclear transcription factor $-\kappa \mathrm{B}$ activation to abrogate dextran sulfate sodiuminduced colitis," Journal of Pharmacology and Experimental Therapeutics, vol. 332, no. 3, pp. 829-839, 2010.

[53] E. O. Farombi, I. A. Adedara, O. V. Awoyemi et al., "Dietary protocatechuic acid ameliorates dextran sulphate sodiuminduced ulcerative colitis and hepatotoxicity in rats," Food \& Function, vol. 7, no. 2, pp. 913-921, 2016. 